\title{
La evolución del régimen sucesoral en el derecho colombiano. A propósito de la Ley 1934 de 2018*
}

\section{Néstor Raúl Charrupi Hernández ${ }^{* \star}$}

Resumen. La tensión que ha existido entre los principios de libertad testamentaria y restricción de la voluntad del testador, presente en diferentes países del derecho anglosajón y continental, fundamentaron la expedición de la Ley 1934 de 2018, que introdujo cambios al régimen de sucesiones colombiano al darle paso a una mayor autonomía y libertad del testador de disponer de su patrimonio con efectos después de su muerte, reforma que preservó algunos rezagos del sistema testamentario restringido, al mantener mecanismos de protección de la expectativa de los legitimarios, situación que requiere una nueva aproximación más acorde con nuestras realidades sociales y familiares.

Palabras Clave: legítima, legitimarios, forzosa, testamento, testador, disposición, donaciones, causante, acervos, patrimonio.

Fecha de recepción: 6 de mayo de 2020. Fecha de aceptación: 28 de agosto de 2020.

Para citar el artículo: Charrupi Hernández, N., "La evolución del régimen sucesoral en el derecho colombiano. A propósito de la Ley 1934 de 2018", Revista de Derecho Privado, Universidad Externado de Colombia, n. ${ }^{\circ} 40$, enero-junio 2021, 437-462, Dor: https://doi.org/10.18601/01234366. n40.15.

El presente escrito es el resultado de un trabajo de investigación en desarrollo realizado dentro del marco de la cátedra de Derecho de Sucesiones de la Universidad Externado de Colombia.

** Universidad Externado de Colombia, Departamento de Derecho Civil, Bogotá, Colombia; docente Especialista en Responsabilidad y Daño Resarcible, Universidad Externado de Colombia, Bogotá, Colombia. Contacto: nestor.charrupi@uexternado.edu.co Orcid: 0000-0003-2754-3307. 


\section{New Successional Legislation in Colombia. Law 1934 of 2018}

Aвstract. The tension which has existed between the principles of testamentary freedom and the restriction of the testator's will, present in different common law and civil law countries, founded the issuance of Law 1934 of 2018. This law introduced changes to the Colombian inheritance regime providing for greater autonomy and freedom to the testator to dispose of her patrimony with effects after her death. This Reform kept some lags from the restricted testamentary system, by upholding protection mechanisms of the expectation of forced heirs; situation that demands a new and more consistent approach with our family and societal realities.

KEYWORDS: forced estate, forced heirs, forced heirship, will, testator, disposition, donations, decedent, inheritance, patrimony.

Sumario. Introducción. I. Tensión entre los principios de libertad testamentaria y restricción de la voluntad del testador. II. Exposición de motivos de la Ley 1934 de 2018. III. Cambios que introdujo la Ley 1934 de 2018. IV. Elementos del sistema de libertad testamentaria restringida. V. Vigencia en el régimen sucesoral colombiano de la figura del primer acervo imaginario. Conclusiones. Referencias.

\section{Introducción}

Las nuevas formas de interacción social dentro de un mundo globalizado incorporan importantes desafíos a las estructuras normativas existentes, exigiendo de estas una oportuna adecuación para responder a las diversas necesidades que cada época demanda de acuerdo con la sociedad a la que sirve. Conforme a ese presupuesto, resulta interesante el análisis exhaustivo de ciertas instituciones propias de la legislación civil colombiana que respondieron a una concepción determinada del devenir social operante, y que requieren hoy de un inaplazable ajuste.

Patente resulta la urgente revisión del régimen sucesoral colombiano, principalmente en lo que a las asignaciones hereditarias forzosas se refiere, y en especial a las figuras de las legítimas y mejoras, instituciones jurídicas heredadas del código civil de Bello que permanecieron inalteradas durante largo tiempo, sin que respondieran a la evolución que las diferentes relaciones de familia han venido evidenciando en nuestra sociedad.

Es por ello que ha sido llamativo para el derecho de sucesiones el reciente cambio legislativo en materia de asignaciones forzosas adoptado mediante la promulgación de la Ley 1934 de 2018, "Por medio de la cual se reforma y adiciona el Código Civil”, cuya vigencia inició el $1 .^{\circ}$ de enero de 2019. La aproximación realizada al espacio de configuración del patrimonio del causante testador se veía las más de las veces bastante restringida debido al estrecho margen de maniobra que aquel tenía -y aún mantiene- sobre el destino del conjunto de bienes que conforman el acervo 
hereditario que está destinado a pasar a aquellos convocados por la ley y/o el testamento a recibirlos, siendo por lo tanto esta reforma útil y necesaria a la luz de las nuevas realidades.

Así las cosas, y en respuesta a las necesidades de la sociedad actual, la Ley 1934 de 2018 modificó parcialmente el régimen de sucesiones al otorgar una mayor libertad al testador al momento de efectuar las disposiciones testamentarias, eliminando la cuarta de mejoras destinada a acrecentar la cuota herencial de los descendientes, dejando en dos partes la masa sucesoral -previas deducciones y agregaciones en razón de las donaciones que hubiere hecho el de cujus-, distribuyéndose la mitad de los bienes para los legitimarios (mitad legitimaria) y la otra para libre disposición. La mitad legitimaria debe ser repartida en partes iguales entre los legitimarios -los cuales fueron determinados en el actual artículo 1240 c.c.-, y la mitad de libre disposición es la parte con la que cuenta el testador para que a su voluntad asigne a quien o quienes él prefiera.

De acuerdo con lo anterior, y en aras de realizar un análisis adecuado de la Ley 1934 de 2018, se divide el estudio de la reforma introducida en seis partes: en la primera, se hace un breve análisis de la tensión existente entre el principio de libertad testamentaria y las regulaciones legales al momento de establecer la restricción de la voluntad del testador; en un segundo apartado, se hace una síntesis de los argumentos principales que fundamentaron la expedición de la Ley 1934 de 2018; en una tercera parte, se muestran los principales cambios que introdujo la nueva normativa en la legislación civil, especialmente en lo que respecta al régimen de sucesiones; en cuarto lugar, se aborda el estudio de los diversos elementos que existen en un sistema de libertad testamentaria restringida, con el fin de establecer cuál es la importancia de los acervos imaginarios dentro de aquel; en un quinto punto, se pone de manifiesto el grave yerro en que incurrió el legislador al mantener un sistema de libertad testamentaria restringida eliminando su principal mecanismo de protección; por último, se proponen algunas conclusiones, dejando el interrogante acerca de las razones por las cuales no se acogió un sistema de plena libertad testamentaria pese a ser este un principio más acorde con la actual realidad social de nuestro país.

\section{Tensión entre el principio de libertad testamentaria y la restricción de la voluntad del testador}

Múltiples y variadas fuentes influenciaron el derecho de sucesiones recogido en nuestro compendio civil, nutriéndose don Andrés Bello, para su elaboración, del derecho romano, postulados religiosos, tradiciones germánicas, el derecho español -en especial, las Siete Partidas y las Leyes de Toro-, el common law y, por supuesto, el código civil francés de 1804, para así adoptar una legislación sucesoral estructurada y basada en diversas concepciones y aproximaciones que la enriquecieron y la posicionaron como novedosa respecto de los desafíos y retos propios que incorporaba el siglo XIX en las nacientes repúblicas americanas. 
Ha existido ardua disputa y controversia, en torno de las asignaciones forzosas, en cuanto a si es preferible dejar con pleno y absoluto arbitrio a los seres humanos para disponer de sus bienes para que tenga efectos después de su muerte, o si su libertad debe ser restringida y limitada en interés de los vínculos que emanan de la familia, principalmente cuando de descendientes y ascendientes se trata.

Se han encontrado en permanente y continúa tensión dos posturas extremas: la de aquellos que han creído que la institución de las legítimas es propia del derecho natural, consustancial a la raza humana, anterior a toda codificación y que se encuentra fijada en el sentimiento que debe orientar las relaciones de familia; y la de quienes sostienen que la necesaria división de la herencia entre los legitimarios no reporta ningún provecho ni resulta conforme con el bienestar de la economía de las nociones y el orden social, toda vez que conduce a que el heredero, seguro de que no podrá ser despojado de su cuota mínima de bienes del causante, no sea emprendedor, productivo ni laborioso por la tranquilidad que la legítima le comporta.

El derecho romano primitivo contemplaba un régimen de libertad testamentaria plena; de hecho, la Ley de las Doce Tablas no incluía la figura de las legítimas, por lo que la libertad de testar era completamente absoluta; de ahí la expresión latina "pater familias uti legassit super pecunia tutelave suae rei ita jus esto"; no obstante, lo anterior fue transformándose en una libertad testamentaria casi plena. De acuerdo con Bonfante $^{1}$, el pater familias, al tener potestades casi absolutas, antes de su deceso y tomando como referencia las aptitudes de sus descendientes, elegía a uno de ellos como su sucesor; como se advierte, el testador podía designar como continuador a quien considerara conveniente, con la única condición de que el heredero escogido fuera miembro de su familia. Ahora bien, con posterioridad se le dio la facultad al pater familias de designar como heredero a una persona extraña o ajena a su grupo familiar, siempre y cuando el testador no tuviera descendencia o que "adoptara" a la persona extraña mediante ese testamento ${ }^{2}$.

Sin embargo, esa libertad testamentaria fue disminuyendo gradualmente con ocasión de la aparición de las figuras de los legados ${ }^{3}$, la donación y el desheredamiento, lo que conllevó la necesidad de evitar las disipaciones del patrimonio de la familia para salvaguardar que los miembros de aquella se quedaran sin patrimonio para subsistir; de esta manera, en el año 40 a.C., se promulgó la lex Falcidia ${ }^{4}$, con la

1 Bonfante, P., Corso di diritto romano. Le successioni, Milano, Giuffrè, 1974, 20 y ss.

2 Colmenares, J., Libertad testamentaria en Roma. Una aproximación a propósito del estado actual de la cuestión en Colombia, México, Instituto de Investigaciones Jurídicas, Universidad Nacional Autónoma de México, 2017, 239.

3 La asignación se llama "legado" y el asignatario, "legatario", cuando se sucede en una o más especies o cuerpos ciertos, como tal caballo, tal casa; o en una o más especies indeterminadas de cierto género, como un caballo, tres vacas, seiscientos pesos, cuarenta fanegadas de tierra, etc.

4 Gai. 2, 227. Finalmente se promulgó la Ley Falcidia, por la que se estableció que el testador no puede legar más de tres cuartas partes de la herencia, de modo que necesariamente el heredero tenga una cuarta parte, y tal disposición se observa hoy (trad. J. A. Colmenares Mantilla). 
que se dispuso que el testador debía dejarle por lo menos un cuarto del patrimonio a sus herederos 5 , siendo este el antecedente de lo que se conoce hoy como "legítima".

Posteriormente, con la influencia de otras culturas, se le brinda un postulado de carácter moral a la limitación impuesta al testador, el cual está relacionado con la obligación de dejar parte de su patrimonio a sus hijos por el simple cariño que les debe; por tal razón, para la primera mitad del siglo III d.C. se introduce la "querella inofficiosae donationis", por la cual se permitió rescindir las donaciones que en exceso hubiera realizado el pater familias y que afectaban la "legítima" de sus herederos, siendo este el antecedente de la figura de los "acervos imaginarios", institución que buscaba proteger los intereses de los herederos forzosos de las acciones del testador que disminuían su patrimonio y de esta manera afectaban su expectativa de herencia.

Respecto a la libertad del testador en el derecho romano, aun cuando fue disminuyendo, debe aclararse que su voluntad seguía siendo el elemento más prominente, dado que podía disponer de la tercera parte de su patrimonio como lo considerara conveniente, dándole primacía a la libertad testamentaria, y restringiéndola únicamente en casos excepcionales.

Para el siglo IV d.C., los postulados religiosos permean diversas instituciones jurídicas en el derecho romano, y la moral cristiana, en su afán de otorgarle una mayor estabilidad al matrimonio ${ }^{6}$, termina por afectar las bases de las reglas de las sucesiones, por lo que en esa época se estableció que los descendientes no podían desheredar a sus ascendientes y viceversa, salvo que mediara justa causa.

Con las invasiones bárbaras en Europa, la influencia del derecho germánico termina por impactar las figuras jurídicas del testamento y su regulación, puesto que los germanos consideraban que el derecho hereditario emanaba única y exclusivamente de los vínculos de sangre, además de que los bienes, en particular los inmuebles, no pertenecían al causante sino que eran de propiedad de la familia, y en esa medida el testador no podía disponer de ellos a su arbitrio ${ }^{7}$.

La Ley de las Siete Partidas, redactada durante el reinado de Alfonso x el Sabio, entre los años 1252 y 1284, en la Ley XVII, del Título I, Parte VI ${ }^{8}$, disponía que la cuo-

5 Los romanos establecieron la legítima de los herederos, llamada Cuarta Falcidia por haberla introducido el tribuno Falcidio. De acuerdo a esta, podía el heredero extraño tomar de cada legado la parte necesaria para completar la cuota de la herencia que siempre debía quedar a salvo. Igualmente, instituyeron la Cuarta Trebeliánica, denominada así por haberla instituido el senadoconsulto trebeliano, por la que el heredero fiduciario tenía derecho de deducir para sí la cuarta parte líquida de los bienes de la herencia, antes de restituirlo al fideicomisario.

6 Berman, H., La formación de la tradición jurídica de Occidente, México, Fondo de Cultura Económica, 1996, 238.

7 MaInAR, R., "De la legítima romana a la reserva familiar germánica”, Revista Internacional de Derecho Romano, n. ${ }^{\circ} 14,2015,1-63$.

8 Partida VI, Tit. Ley XVII: "Et la legítima parte que deben haber los fijos es esta, que si fueren quatro ó dende ayuso, deben haber de las tres partes la una de todos los bienes que hobiere aquel à quien heredan; et si fueran cinco ó mas, deben haber la meatad: et por eso se llama parte legítima, porque 
ta legítima era de un tercio de la porción intestada cuando los herederos eran hasta cuatro, y de la mitad si el número de aquellos ascendía ${ }^{9}$. Existen diversas teorías que fundamentan la instauración de esa limitación; así, para algunos doctrinantes se debió al interés de beneficiar equitativamente a los herederos legítimos, mientras que otros aseguran que se produjo con la intención de debilitar a la nobleza de la época, puesto que, al estar obligados a distribuir su patrimonio entre todos los hijos legítimos, se veía amenazada la relación que tenía la nobleza con la corona ${ }^{10}$, en la medida en que restringía las aspiraciones económicas nobiliarias.

En las Leyes de Toro de 1505, la libertad testamentaria se limitó aún más. La Ley Sexta de esa codificación, estableció como legítimas las cuatro quintas partes de los bienes del testador. Es igualmente necesario tener en cuenta que no fue sino hasta la promulgación de esta ley que los ascendientes fueron catalogados como herederos forzosos, con la condición de que el testador no tuviera descendientes, caso en el cual el testador debía asignarles las dos terceras partes de su patrimonio, y el tercio restante era la porción con la que el testador podía ejercer su plena voluntad ${ }^{11}$. De lo anterior se puede concluir que desde los principales estamentos se les otorgó preferencia a los descendientes sobre los ascendientes ${ }^{12}$.

Ahora bien, la noción de libertad testamentaria continuó limitándose, y se acogió en los diversos modelos de civil law, como es el caso del régimen sucesoral francés acogido en el Code civil français ${ }^{13}$, normativa que tiene como base primordial los preceptos propios de la Revolución francesa en auge para esa época, en donde la eliminación de la libertad de testar fue el resultado de la necesidad de debilitar a la

la otorga la ley á los fijos, et débenla haber libre, et quita, et sin embargo, et sin agravamiento et sin ninguna condición".

9 Iglesias, J., Derecho romano. Historia e instituciones, 11. a ed., Barcelona, Ariel, 1993, 592.

10 Iglesias, Y. y Navarro, D., "La inclusión de la 'legítima' como elemento desestabilizador de la nobleza en la Partida vi de Alfonso x", Revista Canadiense de Estudios Hispánicos, vol. 41, n. 3 , 2017, 547-567.

11 Leyes de Toro, Ley Sexta: "Los ascendientes legítimos, por su orden y línea derecha, sucedan ex testamento et ab intestato á sus descendientes, y les sean legítimos herederos, como lo son los descendientes á ellos, en todos sus bienes, de qualquier calidad que sean, en caso que los dichos descendientes no tengan hijos descendientes legítimos, ó que ayan derecho de les heredar: pero bien permetimos que no embargante que tengan los dichos ascendientes, que en la tercia parte de sus bienes puedan disponer los dichos descendientes en su vida, ó hacer qualquier última voluntad que se guarde, salvo en las ciudades, villas y lugares, do según el fuero de la tierra se acostumbran tornar sus bienes al tronco, ó la raiz á la raiz”.

12 “... conocidas son las reglas capitales sobre el derecho de testar en estos reinos de Castilla. Las personas que tienen hijos o padres, descendientes o ascendientes legítimos, no pueden disponer libremente de todos sus bienes, nuestra legislación, como la romana en sus medios y en sus últimos tiempos, ha reconocido y señalado herederos forzosos, a los cuales no se puede privar de lo que se llama legítima sino por una explícita, terminante exheredación, fundada en causas ciertas y legales". Fragmento tomado de PACHECO, J., Obras jurídicas. Comentario histórico, crítico y jurídico a las Leyes de Toro, t. I, Sevilla, Imprenta de Manuel Tello, 1862, 246.

13 Lira-Urquieta, P., "Introducción”, en Andrés Bello, XII, Código civil de la República de Chile, I, Caracas, Ministerio de Educación, 1954. 
vieja aristocracia, para lo cual era necesario hacer una redistribución equitativa de la tierra, evitando la acumulación del poder mediante la concentración de la riqueza en determinadas familias ${ }^{14}$.

Así mismo, la Novísima Recopilación de Castilla, publicada en el año 1805, continúa contemplando la restricción de la libertad testamentaria, al establecer a los descendientes y ascendientes legítimos como herederos forzosos; algunos doctrinantes insisten en que esta situación demuestra que se quería evitar que la calidad de herederos la tuvieran personas ajenas a la familia ${ }^{15}$.

Por otra parte, los regímenes jurídicos que adoptaron un sistema de common law ${ }^{16}$ tienden a tener normas sucesorales más simples, siendo este el caso del derecho inglés, en el que la institución de las legítimas no existe; es decir, la ley no establece la figura de los asignatarios forzosos, y ninguna porción del patrimonio del causante se destina a los descendientes, ascendientes o parientes de grado más próximo, razón por la cual el testador tiene plena libertad al momento de escoger a sus asignatarios. La figura más afín a la institución de las legítimas se denomina "family provisions"17, y por medio de ella una autoridad judicial, de manera discrecional, dispone a favor de las personas económicamente dependientes del causante una provisión de los bienes que sea suficiente para sobrevivir o para continuar con el nivel de vida acostumbrado, según sea el caso ${ }^{18}$.

Lo anterior resulta interesante, toda vez que nos da luces para entender la institución de las asignaciones forzosas, las cuales son más afines al derecho romano del periodo clásico y posclásico, ostentando una clara influencia del derecho español.

Descendiendo a la legislación sucesoral en nuestro continente, encontramos que don Andrés Bello, debido a su formación inglesa, fue siempre partidario de la libertad de testar; tan fue así que en alguna oportunidad expresó:

En el establecimiento de las legítimas, la filosofía no parece estar de acuerdo con la legislación. Aquel antiguo principio de los Romanos, Pater familias uti legassit... ita jus esto, sería la regla que podría seguirse, si no fuese preciso transigir con las preocupaciones. En el corazón de los padres tiene el interés de los descendientes una garantía mucho más eficaz que la protección de la ley; y el beneficio que deben

14 Weber, M., The Agrarian Sociology of Ancient Civilizations, 1909.

15 VÁzQuez, A., Fundamentos históricos y jurídicos de la libertad de testar, Vigo, Universidad de Vigo, 2018, 250 y ss.

16 En el Estado de Luisiana (Estados Unidos), el cual cuenta con una clara influencia del derecho francés y español, se adoptó en su código civil (arts. 1494 a 1514) la figura de los Forced Heirship que constituye un sistema de herencia forzada donde se presenta una provisión adecuada para los dependientes del causante testador.

17 Figura afín, guardadas las proporciones, con las de alimentos y porción conyugal de nuestro ordenamiento jurídico.

18 Anderson, M., "Una aproximación al derecho de sucesiones inglés", Anuario de Derecho Civil, Agencia Estatal Boletín Oficial del Estado, vol. 59, n. 3, 2006, 1245 ss. 
éstos alguna vez a la intervención del legislador, es más que contrapesado por la relajación de la disciplina doméstica, consecuencia necesaria del derecho perfecto de los hijos sobre casi todos los bienes del padre. Así vemos que ni aun las legítimas fueron conocidas en Roma mientras a la sombra de las virtudes republicanas se mantuvieron puras las costumbres y severa la disciplina doméstica. Las legítimas no son conocidas en la mayor parte de la Gran Bretaña y de los Estados Unidos de América; y tal vez no hay países donde sean más afectuosas y tiernas las relaciones de familia, más santo el hogar doméstico, más respetados los padres o procurados con más ansia la educación y establecimiento de los hijos... Cuanto más suave el yugo de las leyes, más poderosa es menester que sea la venerable judicatura que la naturaleza confiere a los padres. - Y ¿cómo suplir el afecto paternal o filial si llegase alguna vez a extinguirse? Si pasiones depravadas hacen olvidar lo que se debe a aquellos de quienes hemos recibido el ser o a quienes lo hemos transmitido, ¿de qué sirven las preocupaciones del legislador? ${ }^{19}$.

A pesar de esa opinión, y con el ánimo de conciliar la posición mayoritaria que se encontraba en contravía de aquella que propugnaba la libertad al testar, no sin disputa y protesta, terminó transigiendo con las legítimas, por las arraigadas costumbres y prejuicios existentes en las sociedades latinoamericanas de la época, razón por la cual en nuestro código civil ${ }^{20}$ se privilegió el principio de la restricción testamentaria en interés de la familia, sacrificándose el de plena libertad de disposición de los bienes del testador para que tenga efectos después de su muerte.

Es por ello que el Proyecto de Código Civil Chileno de 1855 en su artículo 1063 establecía que la elección de un asignatario, sea absolutamente, sea de entre cierto número de personas, no dependerá del puro arbitrio ajeno, postulado que sin duda establecía la libertad del testador de escoger a sus asignatarios; no obstante, más adelante el artículo 1167 indicaba que las asignaciones forzosas son las que el testador está obligado a hacer, y que se suplen cuando no las ha hecho, aun con perjuicio de

19 Nota de Bello al art. 5 del tít. 8 del Proyecto de 1811: véase Bello, A. Obras completas, vol. xxvi, t.

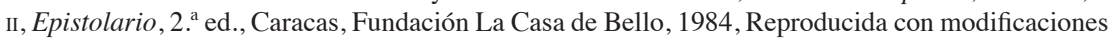
en la nota al art. 1343 núm. 4 del Proyecto de 1853 y en las notas publicadas en la segunda edición del Código por la imprenta de El Mercurio de Valparaíso.

20 El 10 de julio de 1856, Manuel Ancízar, científico, diplomático y político colombiano, se dirigió a Andrés Bello en los siguientes términos: "se ha dado en mi país el último paso para establecer por fin la completa independencia municipal de las secciones, las cuales en lo sucesivo se gobernarán por sí mismas siendo dueñas de todos sus intereses particulares. Entre las nuevas atribuciones que están a punto de conferirse a las grandes provincias que se organizarán dentro de un año con el nombre de Estados, se numera la de darse cada cual la legislación civil y penal que convenga. Pues bien, de varias partes me han manifestado el deseo de poseer el Código civil que U. elaboró para Chile, y me han hecho el encargo de solicitarlo. Es seguro que U. con su bondad genial, se prestará a satisfacer aquel deseo recomendable, pues se trata de aprovecharnos del saber de otros países y de preferir a cualesquiera otras las doctrinas legales profesadas en nuestra Sur América, lo cual puede ser un primer paso dado hacia la apetecida unidad social de nuestro continente". Es importante resaltar que mediante el Ministerio de Relaciones de Chile se enviaron a nuestro país cuatro ejemplares del código civil que debía regir el 1. ${ }^{\circ}$ de enero de 1857. Bello, A., Obras completas, cit., 333. 
sus disposiciones testamentarias expresas, las cuales corresponden a "los alimentos que se deben por ley a ciertas personas, la porción conyugal, las legítimas y la cuarta de mejoras en la sucesión de los descendientes legítimos"; así mismo, en el artículo 1181 se encontraba el concepto de legítima, definida allí como aquella cuota de bienes de un difunto que la ley les asigna a ciertas personas llamadas legitimarios; seguidamente, el artículo 1184 establecía el porcentaje que corresponde a las legítimas, siendo este el $50 \%$ de los bienes, previas deducciones y agregaciones de ley, y otro $25 \%$ que correspondía a las mejoras que debían hacerse a los descendientes; es decir que el testador solo podía disponer a su arbitrio del restante $25 \%$, tal como quedó establecido en la legislación colombiana hasta la expedición de la Ley 1934 de 2018.

De lo dicho anteriormente puede entenderse que el régimen sucesoral de los países ligados al civil law ${ }^{21}$, por sus antecedentes y fundamentos históricos, ven en las asignaciones forzosas, en especial en la legítima ${ }^{22}$, una institución que refuerza los

21 Por ejemplo, en el caso de la legislación civil italiana, al igual que sucede en España, Francia y Alemania, se establece el régimen de legítimas, y se indica que son legitimarios los descendientes, el cónyuge sobreviviente y los ascendientes (únicamente en caso de ausencia de hijos), aunque se establecen diferentes porcentajes dependiendo de la cantidad de hijos. Respecto del porcentaje al que asciende la legítima, se tiene lo siguiente: en caso de existir un único hijo, será un medio del patrimonio hereditario, y si son dos o más hijos, será de dos tercios del patrimonio (art. 537); si no hay hijos pero sí cónyuge, será de un medio del patrimonio (art. 540); si el cónyuge concurre con un hijo, a este último le corresponde un tercio, y al cónyuge un cuarto, y si el cónyuge concurre con dos o más hijos, a los hijos les corresponde un medio del patrimonio y al cónyuge un cuarto (art. 542); si concurre el cónyuge con los ascendientes, será para el cónyuge un medio del patrimonio, y para los ascendientes un cuarto (art. 544); por último, si solo hay ascendientes, la legítima será un medio del patrimonio del causante (art. 538). Por otra parte, debe tenerse en cuenta que en caso de que el testador no respete el límite impuesto por las legítimas, este hecho no afecta la validez del testamento en la medida en que no sea impugnado por los legitimarios.

22 En España, el derecho común establece una reserva del patrimonio del causante para determinadas personas; el código civil indica al respecto que la "legítima es la porción de bienes de que el testador no puede disponer por haberle reservado la ley a determinados herederos llamados por esto herederos forzosos", siendo herederos forzosos los descendientes, los ascendientes a falta de descendientes, y el cónyuge. La legítima de los descendientes corresponde a las dos terceras partes del haber hereditario y la de los ascendientes es la mitad, salvo que aquellos concurran con el cónyuge, caso en el cual será de un tercio. En cuanto a las reglas que se aplican en las comunidades autónomas, tenemos lo que sigue: (i) Aragón: los legitimarios son los descendientes, a quienes les corresponde la mitad del patrimonio, y el cónyuge que tiene el usufructo universal; (ii) Cataluña: los legitimarios son descendientes, ascendientes y el cónyuge sobreviviente; los primeros tienen derecho a un cuarto del haber, los ascendientes (solo los padres) a otro cuarto, y el cónyuge hasta a un cuarto en caso de que no tenga recursos propios; (iii) Galicia: solo son legitimarios los descendientes y el cónyuge; a los primeros les corresponde una legítima de un cuarto, y el cónyuge tendrá un cuarto en usufructo si concurre con descendientes, en caso contrario será la mitad del haber en usufructo; (iv) Mallorca y Menorca: los legitimarios son los descendientes, ascendientes (solo padres) y cónyuge; a los primeros les corresponde un tercio si son hasta cuatro hijos, en caso de ser más será de la mitad del haber, y los segundos ostentan una legítima de un cuarto, pero si solo hay ascendientes será la mitad; y respecto de los últimos, si concurren con descendientes, será de la mitad en usufructo. (v) Ibiza y Formentera: solo son legitimarios los descendientes (un tercio si son hasta cuatro hijos, en caso de ser más será de la mitad del haber, y los ascendientes (según las reglas del derecho común); (vi) País Vasco: son legitimarios los descendientes, a los que les corresponde un tercio del patrimonio, y el cónyuge (si concurre con descendientes será la mitad en del usufructo, y en caso contrario, será 
vínculos entre padres e hijos, fortaleciendo el afecto paternal y la unión del núcleo familiar como base fundamental del Estado, mientras que los regímenes propios del common law han confiado en que el testador habrá de regirse por imperativos de prudencia y justicia ${ }^{23}$.

Evidente y clara tensión se observa entre las dos posiciones expuestas: de una parte, la de aquellos que han defendido la libertad testamentaria ejercida dentro de los cauces de la prudencia y la sana lógica, despojando al legislador de las ataduras impuestas al testador, en aras de evitar la complicación de las particiones, las controversias e interminables pleitos familiares que ocasionan daño en aquellos herederos que pasivamente esperan su cuota sin propender por la construcción de lo propio; por la otra, la de quienes, de la mano del derecho natural, de la moral social, y por razones de compasión familiar, afecto filial y piedad, se inclinan por no dejar sin fortuna, y mucho menos en la miseria, a sus parientes próximos, todo lo anterior para privilegiar a la familia como estructura fundante de la sociedad y del Estado.

\section{Exposición de motivos de la Ley 1934 de 2018}

El proyecto de Ley n. 066 de 2016, "Por medio del cual se reforma y adiciona el Código Civil", fue radicado el 4 de agosto de 2016 en la Secretaría General de la Cámara, y publicado en la Gaceta del Congreso n. ${ }^{\circ} 602$ de 2016, propuesto por los representantes a la Cámara Rodrigo Lara Restrepo (ponente), Carlos Abraham Jiménez López, Jorge Enrique Rozo Rodríguez y José Ignacio Mesa Betancur, donde se propuso ampliar la libertad de testar por medio de la reducción de las legítimas a una cuarta parte de la masa sucesoral, y la eliminación de la cuarta de mejoras, con el fin de permitir la libre disposición de las tres cuartas partes de los bienes, sin perjuicio de la porción conyugal y de los alimentos que por ley se deban. Igualmente, propuso una excepción a esa regla general respecto a la pequeña propiedad rural, a fin de evitar la excesiva fragmentación de la tierra en microfundos ${ }^{24}$, entre otras modificaciones.

Para este fin, la exposición de motivos se centró en cuatro argumentos fundamentales, consistentes en:

a) La imposición de un criterio de igualdad absoluta entre los herederos de un determinado causante es una injerencia excesiva del Estado en la esfera personal de los individuos.

las dos terceras partes). (vii) Navarra: existe libertad respecto de los descendientes, los ascendientes no son legitimarios, y con relación al cónyuge tendrá el usufructo universal; (viii) Tierra de Ayala: hay plena libertad testamentaria, adoptando un régimen en el que no existe institución similar a las legítimas.

23 Carrizosa, H., Sucesiones. Donaciones. Estudio sobre el libro tercero del código civil, 5. a ed., Bogotá, Lerner, 1966, 382.

24 Exposición de motivos de la Ley 1934 de 2018. 
b) El mérito como principal elemento para la consecución de la riqueza.

c) El sistema legal colombiano que regía la sucesión por causa de muerte atendía a necesidades que no correspondían a la realidad de la sociedad colombiana actual, y por ello, la pertinencia de esa ley respecto de las nuevas realidades familiares.

d) La importancia de la libertad de testar en las pequeñas empresas familiares, y en materia de tierras.

Motivos, todos ellos, que serán explicados a continuación con el fin de comprender la relevancia de los cambios normativos que trae consigo la Ley 1934 de 2018, y las razones por las cuales el legislador consideró que eran necesarios, atendiendo a la dinámica del derecho de cara a los nuevos acontecimientos sociales.

\section{A. La no injerencia excesiva del Estado}

Sobre este punto en particular, la exposición de motivos del proyecto de ley realizó un recuento histórico de las diferentes culturas que tienen una libertad testamentaria en mayor o menor grado. Así por ejemplo, en Francia -lugar de donde proviene la cultura jurídica que ha regido nuestro código civil-, la Revolución introdujo el principio de igualdad, el cual fue aplicado a todo tipo de normativa, incluida la ley de herencia; de esta manera la restricción de la libertad testamentaria, que es notoria en la codificación francesa, tiene como motivación la "necesidad de destruir las bases agrarias del poder de la vieja aristocracia" 25 . Con dicha restricción se esperaba entonces llegar a una distribución más equitativa de la tierra, impidiendo la aglomeración del poder a través de la concentración dinástica de la riqueza ${ }^{26}$, y en consecuencia mejorar las condiciones de vida de los campesinos.

Bajo esa premisa, para ese preciso momento histórico, en el que se vivía una coyuntura social determinada por la evidente desigualdad de las clases sociales, existía un fundamento para permitir la injerencia del Estado en los actos propios del testador, materializada en la imposición de medidas que obligaban al testador a dar un trato igualitario a sus hijos al momento de disponer de su patrimonio después de su muerte 27 .

25 Ibíd

26 Ibíd.

27 En el código civil fránces fue establecida la institución de las legítimas, solo que en esta legislación se le denomina "reserva hereditaria", y se define como la parte de los bienes y derechos sucesorios que la ley asegura libre de cargas a ciertos herederos llamados reservatarios, si son llamados a la herencia y la aceptan. La cuota disponible es la parte de los bienes y derechos que no está reservada por la ley y de la que el difunto puede disponer libremente; respecto de quienes constituyen los beneficiarios de esa reserva, tenemos a los descendientes (art. 913 del Code civil) y el cónyuge sobreviviente (art. 914 ibíd.); con relación a los primeros, la reserva hereditaria varía según el número 
A pesar de lo anterior, la causa de la injerencia del Estado en la esfera privada del testador con el pasar de los años ha perdido su objetivo, y se ha convertido en un obstáculo para disfrutar de otros derechos, convirtiéndola en una figura antidemocrática, en la medida en que la libertad de testar encuentra su base en dos pilares fundamentales: por un lado, la libertad de elegir moralmente, y por el otro, el derecho de propiedad. En este orden de ideas debe entenderse que la decisión de a quién heredar y cómo heredar es una determinación eminentemente moral, que debe ser acorde a los valores del propio individuo, y por ende corresponde a una decisión particular en la que el Estado no debería intervenir.

En efecto, le asiste razón al Estado en querer sufragar las determinaciones testamentarias del causante cuando aquel no las haya dejado contempladas en un testamento, caso en el cual resulta aceptable la tesis de que por determinación legal se imponga un trato igualitario a los herederos; no obstante, cuando el testador se encuentra en ejercicio pleno de sus facultades para elaborar el testamento, es apenas justo que el Estado intervenga lo menos posible, con el fin de que sea el mismo testador quien adjudique la partición de sus bienes teniendo en cuenta su particular criterio.

\section{B. El mérito para la consecución de la riqueza}

Dentro del Estado social de derecho existe la libertad de mercado, la cual encuentra sus cimientos en los principios de propiedad, libertad e igualdad. Estos principios pueden presentar tensiones, como la referida a la necesidad de reconciliar el derecho individual de testar -bajo las premisas del mérito y la obtención de riqueza por medio de las virtudes y el esfuerzo realizado- con el derecho de trato igualitario entre los herederos. Por ejemplo, en caso de que el testador estime que alguno de sus herederos ha hecho mayores contribuciones a la familia, o sea el que mejor visión tiene para las inversiones, o simplemente haya estado más pendiente de su causante, podrá considerar que merece tener una mayor participación en su herencia o aun la totalidad de esta; o, al contrario, podrá estimar que sus herederos no merecen el patrimonio que con tanto esfuerzo él adquirió y prefiera dárselo a un tercero; sin embargo, si se permitiesen estos dos últimos escenarios se estarían menoscabando los intereses de los demás herederos, pues no se beneficiarían del patrimonio del testador.

En esta medida, el ordenamiento jurídico colombiano vigente hasta el 31 de diciembre de 2018 establecía que este no podía disponer de parte importante de su pa-

de hijos del causante: así, la reserva será de un medio si tuviera solo un hijo, de dos tercios si tuviera dos hijos y de tres cuartos si tuviera más; ahora bien, respecto del cónyuge, se considera como reservatario en caso de no existir descendientes, y en esta medida la reserva corresponde a una cuarta parte del caudal hereditario. El anterior orden establecido para los reservatarios corresponde a una modificación que introdujo la Ley 2006-728 del 23 de junio de 2006, la cual terminó con la reserva de los ascendientes y, además, adoptó el pacto sucesorio que se encuentra en el derecho alemán, el cual permite la renuncia a la acción de reducción de donaciones y liberalidades. 
trimonio ${ }^{28}$, puesto que debía respetar las legítimas rigurosas y la cuarta de mejoras, y así, solo podía disponer libremente de un $25 \%$ de su patrimonio para asignárselo a quien él considerase mejor.

Es por lo anterior que se insiste en que la herencia obligatoria o ley de reparto por igual, entendida esta como la disposición de los bienes por el solo vínculo de sangre o civil, promueve que los herederos se enriquezcan con un patrimonio que no han trabajado, perpetuando la concentración de las fortunas en ciertas familias, lo que genera mayores desigualdades sociales. Debido a esto el mérito, es decir, la capacidad que tiene cada persona para salir adelante gracias a su trabajo y esfuerzo, debe ser el pilar en el que se fundamente la adquisición de la riqueza.

En ese sentido, la exposición de motivos señala que "la contradicción radica en el hecho de que para determinar la posición económica de una persona importa más lo heredado que el esfuerzo realizado. Esto entra en contravía de las promesas de una economía liberal de mercado, donde el trabajo honesto y la educación representan los principales mecanismos de ascenso social"29.

Así, esta ley buscó reforzar el papel que juega el mérito dentro de las nuevas formas de familia, con el fin de lograr una mayor participación de los integrantes que la conforman, lo que generaría una mejor relación entre causantes y herederos.

\section{La legislación colombiana debe estar acorde con las nuevas realidades familiares}

Como se indicó en párrafos anteriores, la legislación civil colombiana tiene sus orígenes en el código civil francés de 1804, es decir que tiene como base unos principios que buscaban responder a las coyunturas propias de esa época. De ahí que sea deber del legislador colombiano plantear nuevos instrumentos normativos que respondan a las circunstancias sociales actuales y permitan la materialización de los principios democráticos establecidos en la Constitución Política de $1991^{[30]}$.

En esta medida, debe identificarse que la herencia constituye un pilar fundamental en la estabilidad intergeneracional de las estructuras sociales, puesto que

28 Lo anterior, sin perjuicio de la aplicación del principio de la dignidad sucesoral que se predica de todo asignatario, consistente en la situación jurídico valorativa o condición de mérito que le permite a un heredero retener y/o recoger la herencia de su causante (aplicación de las figuras jurídicas de la indignidad y el desheredamiento).

29 Exposición de motivos de la Ley 1934 de 2018.

30 Por ejemplo, para el derecho de sucesiones alemán, la figura de las legítimas cumple una finalidad tan relevante que se encuentra protegida constitucionalmente; de hecho, una importante sentencia proferida por el Tribunal Constitucional Federal alemán (BVerfGE), del 19 de abril de 2005, BvR 1644/00, 188/03, publicada en la recopilación del BVerfGE 112, 332 ss., estableció: "la legítima de los descendientes es un valor protegido constitucionalmente del que aquellos no pueden verse privados y cuya percepción no puede hacerse depender de una previa situación de necesidad". No obstante lo aquí expresado, el Tribunal también ha establecido que la legítima es un derecho a una reclamación dineraria que puede ser ejercitado por el legitimario frente al heredero, cuyo ejercicio es voluntario y no imperativo. 
fundamenta la continuidad de la familia, y la libertad testamentaria es la forma más adecuada para consolidar dicha estabilidad, sin mencionar que cobija a las diferentes uniones que actualmente constituyen núcleos familiares y promueve lazos de solidaridad entre los integrantes de estos ${ }^{31}$. Por lo anterior es posible afirmar que la libertad testamentaria trasciende a las nuevas tendencias y fortalece los lazos existentes entre las personas que conforman un determinado núcleo familiar, promoviendo vínculos de calidad entre testador y herederos.

En este punto debe indicarse que el derecho de testar tiene su base en la libertad con que el testador cuenta para disponer de sus bienes, y en esta medida debería poder hacerlo de la misma manera como lo haría por un acto entre vivos. Sobre este punto, Claro afirma que "[e]s, por lo mismo, más conforme a los principios fundamentales del derecho el sistema de libertad de testar y preferible al sistema de las legítimas y mejoras; porque esa libertad permite al testador cumplir con el conjunto de deberes que las relaciones de su vida le han creado y que los más elementales principios de justicia reclaman que sean cumplidos" 32 .

Teniendo en cuenta lo anterior, es preciso indicar que el sistema de libertad testamentaria es el que resulta ser más conforme a derecho, no solo porque respeta la naturaleza del hombre en virtud de que constituye un acto de mera liberalidad disponer de los bienes a su arbitrio, sin perjuicio, claramente, del cumplimiento del pago de las obligaciones que se deban por ley a otras personas, sino que es el sistema que mejor responde a las estructuras familiares que se encuentran presentes en la sociedad actual ${ }^{33}$.

\section{Importancia de testar frente a pequeñas empresas y microfundos}

Este asunto debe ser dividido en torno a la explicación de cada una de las variables que lo componen, en la medida en que fue propuesto un régimen distinto para cada una de ellas. Respecto a las pequeñas empresas familiares, la Ley 1934 de 2018 fue concebida como un mecanismo para ayudarlas a perdurar en el tiempo gracias a la percepción de continuidad; en cambio, respecto a la injerencia de esta ley en lo relativo a la familia campesina que tiene porciones pequeñas de tierra, se buscó no dividir su propiedad en microfundos, por lo que sus disposiciones no son aplicables

31 En la ponencia de segundo debate, el representante Lara Bonilla indicó al respecto: "Por lo tanto, en un régimen de mayor libertad testamentaria, la expectativa de la herencia puede ser usada por el testador para asegurar un apoyo intergeneracional en el seno de la familia, fortaleciendo la unidad de la misma. La expectativa de heredar, así como cualquier transferencia inter-vivos. Puede promover vínculos de solidaridad entre las generaciones y disminuir los nacimientos fuera del matrimonio".

32 Claro, L., Derecho civil chileno y comparado. De la sucesión por causa de muerte, Santiago, Nascimento, 1942, 242.

33 Gómez, M. E., “Aspectos patrimoniales en las relaciones de familia consagradas en el Código de Andrés Bello y su vigencia en la sociedad contemporánea”, en NAVIA, F. y Chinchilla, C. A. (eds.), La vigencia del código civil de Andrés Bello. Análisis y prospectivas en la sociedad contemporánea, Bogotá, Universidad Externado de Colombia, 2019. 
a las sucesiones testadas en las que se dispongan predios con una extensión inferior a cuatro unidades agrícolas familiares (UAF) ${ }^{34}$.

Respecto a las pequeñas empresas, se insiste en que la mejor alternativa para promover los flujos de ingresos en las empresas familiares consiste en instaurar un sistema de libertad testamentaria plena. Lo anterior por varias razones: 1. El fundador de la empresa familiar -testador- tiene la potestad para decidir, con base en su experiencia, cuál de sus herederos cuenta con mejores capacidades y habilidades para aprovechar los recursos fruto de la actividad de la compañía; y, 2. El testador tendría el derecho de decidir quién, a su juicio, tiene verdaderos méritos para que le sea reconocida una mayor participación en la empresa, o quién tiene el potencial requerido para manejarla.

Un estudio realizado por la firma Deloitte ${ }^{35}$ mostró que la mayoría de las pequeñas empresas son vendidas por la familia o entran en insolvencia ${ }^{36}$ durante la primera generación. La principal causa de ello es que la gran mayoría de empresas familiares no cuentan con una gestión documental que facilite o precise los procedimientos a seguir cuando el socio fundador fallece; otra causa es que los herederos del pionero no cuentan con las capacidades de dirección y manejo requeridas para determinado negocio, esto sin mencionar las disputas entre los herederos tendientes a determinar quién tendrá el control de la empresa.

Todo lo anterior implica que la conservación de la empresa familiar depende de la manera como se abordan los procesos de sucesión, y una mayor libertad testamentaria ayudaría en ese sentido, al darle la facultad al fundador de determinar cuál de sus herederos tiene las mejores habilidades para continuar con el negocio, lo que implica una mejor asignación de los activos, además con implicaciones a nivel macroeconómico, como la generación de empleo, el aumento de la capacidad productiva, el incentivo y fortalecimiento de la inversión extranjera, entre otros aspectos.

34 La unidad agrícola familiar en Colombia es descrita como: "La empresa básica de producción agrícola, pecuaria, acuícola o forestal cuya extensión, conforme a las condiciones agroecológicas de la zona y con tecnología adecuada, permite a la familia remunerar su trabajo y disponer de un excedente capitalizable que coadyuve a la formación de su patrimonio" (art. 38 de la Ley 160 de 1994), y tiene como fin mejorar el ingreso y la calidad de vida de la población campesina en Colombia.

35 Deloitte, Sucesión en la empresa familiar, Boletín Gobierno Corporativo, 2010. Este es el informe más reciente de esta entidad. En el mismo sentido, véase Revista Semana, Empresas de familia: ¿por qué fracasan?, [en línea], Bogotá, 9 de mayo de 2015, disponible en: https://www.semana. com/economia/articulo/empresas-familiares-por-que-no-sobreviven/441465-3 [consultado el 3 de agosto de 2020]; El FinANCIERo, “ ¿Por qué suelen fracasar las empresas familiares?”, [en línea], Costa Rica, 10 de abril de 2016, disponible en: https://www.elfinancierocr.com/gerencia/por-quesuelen-fracasar-las-empresas-familiares/2KD4Jw6EKVAGDM2CVwEvXw2KEM/story/ [consultado el 3 de agosto de 2020]; Cincodías, El PAís, "El 80\% de empresas familiares no pasa de la tercera generación”, [en línea], Madrid, 23 de mayo de 2016, disponible en: https://cincodias.elpais.com/ cincodias/2016/05/23/pyme/1463959556_151014.html [consultado el 3 de agosto de 2020].

36 El régimen judicial de insolvencia en Colombia se encuentra regulado en la Ley 1116 de 2006 (actividades empresariales), en la Ley 1380 de 2010 (persona natural no comerciante) y en la Ley 1564 de 2012 (código general del proceso), además de en el Decreto Reglamentario 2677 de 2012 y en el Decreto Legislativo 560 de 2020. 
Respecto a los microfundos, la Ley 1934 de 2018 tuvo un enfoque más restrictivo, y no permitió que a los propietarios de tierra cuya cabida fuera inferior a cuatro unidades agrícolas familiares (UAF) les fuera aplicable el régimen de legítimas planteado; lo anterior, con la finalidad de no continuar fragmentando la pequeña propiedad rural y así lograr un uso intensivo de la tierra por parte de los campesinos, con un mejor aprovechamiento de los recursos agrarios.

Este es un claro ejemplo de cómo el derecho debe responder a problemáticas actuales que afectan esferas propias de la realidad social y económica colombiana, como lo es la de la distribución de la tierra en las áreas rurales, especialmente, en lo que respecta a la pequeña propiedad, cuya fragmentación impide su adecuado aprovechamiento económico.

\section{Cambios que introdujo la Ley 1934 de 2018}

A pesar de que en el proyecto de ley estaba contemplado ampliar la porción de libre asignación -que con la normativa anterior era solamente del 25\%-, a un 75\%, eliminando la cuarta de mejoras y reduciendo a un cuarto la legítima, propiciando así un modelo dirigido a otorgarle una mayor libertad al testador, una vez concluido el primer debate legislativo se estableció que esa ampliación debería ser solo del 50\%, y no del $75 \%$, quedando establecido que un $50 \%$ de la masa sucesoral estaría destinado a legítimas rigurosas, y el otro $50 \%$ a libre disposición ${ }^{37}$.

Igualmente, con esta ley se cambió la redacción del artículo 1045 c.c., incluyendo una variación en el primer orden sucesoral, en el sentido de hablar de descendientes de grado más próximo, y no de la dispendiosa y odiosa clasificación que se hacía de los diferentes hijos, además de introducir una variación al artículo 1240 c.c., al preceptuar quiénes se considerarán legitimarios, esto es, los descendientes, personalmente o representados, y los ascendientes.

37 En el contexto del derecho latinoamericano encontramos, por ejemplo, que la legislación peruana respecto de las legítimas establece que aquellas son de beneficio de los descendientes, ascendientes y el cónyuge, y en esa medida los artículos 725 a 727 c.c. establecen que en caso de existir descendientes o cónyuge la legítima corresponde a los dos tercios del patrimonio, y en caso de que solo existan ascendientes corresponde a la mitad de los bienes del causante; en caso de no existir ninguno de ellos, el testador podrá disponer libremente de la totalidad de sus bienes. Por su parte, la legislación venezolana también establece la institución de la legítima, e indica que legitimarios son los descendientes, ascendientes y el cónyuge sobreviviente, siempre que no esté separado legalmente de bienes, quienes concurren y son excluidos y representados según el orden y las reglas establecidas para la sucesión intestada; de esta manera, los ascendientes solo tienen derecho en caso de no existir descendientes o cuando estos hayan sido declarados indignos o hayan renunciado; igualmente, establece que la legítima asciende al 50\% del patrimonio (arts. 883 ss. c.c.). Por último, Brasil establece un régimen de legítimas que denomina de "herederos necesarios", y lo regula a partir del artículo 1845 c.c., indicando que aquellos son los descendientes, ascendientes y el cónyuge; establece como legítima de aquellos el $50 \%$ de los activos de la herencia, y así lo ratifica en el artículo 1789 c.c., en el que se establece que en caso de existir herederos necesarios el testador solo puede tener la mitad de la herencia, haciendo referencia a que este es el porcentaje del que puede disponer el testador a su arbitrio. 
Así mismo, se eliminaron algunos artículos del código civil ${ }^{38}$, pero esa derogatoria se realizó de manera poco prudente, puesto que se limitó a excluir del ordenamiento jurídico las disposiciones relativas a la cuarta de mejoras o aquellos apartes que contuvieran esa denominación, sin hacer un análisis previo de las consecuencias que dicha eliminación traería consigo. Un ejemplo de ello se encuentra en la derogatoria del artículo 1243, disposición en la que se encontraba el concepto de acervo imaginario, figura jurídica que buscaba proteger los intereses y la igualdad en la división de la herencia entre los herederos del causante, y al eliminarlo dejó en entredicho la figura de las legítimas en sí mismas consideradas. Así, el artículo 20 de la Ley 1934 de 2018, de manera expresa, dijo derogar las disposiciones contenidas en el artículo 1243 c.c., esto es, la normativa que establecía el primer acervo imaginario, no obstante lo cual dejó vigente el artículo 1226, que determina las asignaciones forzosas, estableciendo entre ellas a la legítima; el artículo 1244, que dispone lo relacionado con el segundo acervo imaginario, y el artículo 1256, que establece la imputación a las legítimas de aquellas donaciones realizadas por acto entre vivos por el causante a legitimarios (anticipo de legítima), situación que abordaremos en detalle más adelante.

Por otra parte, habrá de decirse que permanecen algunas instituciones relativas a las asignaciones forzosas; por ejemplo, se mantuvo el concepto de legítima efecti$\mathrm{va}^{39}$, estableciendo que acrece a las legítimas rigurosas toda aquella porción de los bienes de que el testador ha podido disponer con absoluta libertad y no ha dispuesto, o cuando, habiéndolo hecho, su disposición no tuvo efecto (art. 1249 c.c.). De esa manera, la porción sobre la que no dispuso nada o no tuvo efecto su disposición, deberá sumarse a las legítimas rigurosas, en partes iguales, eso sí, dejando en claro que este "acrecimiento" 40 no aprovecha al cónyuge sobreviviente ${ }^{41}$, en el caso de optar por porción conyugal.

Igualmente, se mantuvo lo relativo a la protección que se les brinda a los legitimarios respecto de las donaciones revocables e irrevocables ${ }^{42}$ que el causante hubie-

38 La Ley 1934 de 2018 derogó los artículos 1243, 1252, 1253, 1259 y 1262 c.c.

39 La diferencia entre la legítima rigurosa y la efectiva no resulta de mayor utilidad, pues sirve solo para dejar en claro que aquel que opte por el derecho a porción conyugal no se aprovechará de los aumentos que se den como consecuencia de no haber dispuesto el causante de lo que por concepto de libre disposición tuviere.

40 Este vocablo que utiliza el código civil no lo es propiamente en el sentido técnico que designa el derecho de acrecer, debido a que no se trata de un verdadero acrecimiento sino de un aumento o agregación.

41 Importante analizar este aspecto de conformidad con lo establecido por la Corte Constitucional en la sentencia C-283 de 2011 en el sentido de extender los efectos de las disposiciones relativas a la porción conyugal, al compañero o compañera permanente del mismo o diferente sexo.

42 Las donaciones revocables son legados anticipados y están sometidos a las reglas de estos. La diferencia entre unos y otros estriba en la forma de imputarlos a la sucesión, ya que aquellas se harán por el valor de las cosas donadas al tiempo de la entrega. Las donaciones revocables o donaciones por causa de muerte constituyen un acto jurídico unilateral por el cual una persona da o promete dar a otra una cosa o derecho para después de su muerte, pudiendo revocarse al arbitrio del donante. 
re hecho a extraños, que sean consideradas inmoderadas o excesivas frente al margen de liberalidad que tenga respecto de su patrimonio, y que potencialmente conduzcan a una aminoración, reducción o adelgazamiento de las asignaciones forzosas ${ }^{43}$.

En síntesis, los cambios que introdujo esta normativa se ciñen a: la determinación y clasificación de las asignaciones forzosas, estableciendo las personas que se consideran como legitimarios; la eliminación de la cuarta de mejoras y, por ende, el aumento de la porción o cuota de libre disposición; la determinación de las consecuencias para un asignatario derivadas de hipótesis de indignidad o desheredamiento, y la eliminación de lo relativo a la colación imaginaria de donaciones realizadas por el causante en vida a los legitimarios.

\section{Elementos del sistema de libertad testamentaria restringida}

De lo dicho en precedencia tenemos que en Colombia no existe libertad absoluta de testar, pues ella se encuentra limitada por las asignaciones forzosas que el testador está obligado a efectuar, y sustituyen sus disposiciones expresas cuando estas no cumplen con los requisitos legales. Lo anterior en consonancia con la existencia de tres elementos que orientan el sistema de restricción testamentaria expuesto: el primero es de carácter personal, y hace referencia a los individuos que por ley deben estar incluidos dentro del testamento, que es lo que se conoce como "legitimarios"; el segundo es de carácter patrimonial, que tiene que ver con la porción, porcentaje o cuota de bienes del acervo herencial que deben tener los legitimarios: de allí la existencia de lo que se conoce como el sistema de cuartas; y por último, está el elemento de carácter cautelar, el cual corresponde a los mecanismos con los que cuentan los legitimarios para proteger su expectativa, que es lo que se conoce como los acervos imaginarios.

La legítima, entonces, representa esa cuota mínima de la herencia reservada por la ley a ciertos herederos que se denominan legitimarios, lo que configura una asignación forzosa; esto quiere decir que el causante no puede cercenarla sino en aquellos eventos en que un legitimario disminuye o elimina el mérito para suceder en todo o en parte su cuota herencial (desheredamiento $)^{44}$. En otras palabras, la legí-

Por su parte, las donaciones irrevocables son los verdaderos anticipos de legítima, debido a que esta sale efectivamente del patrimonio del donante mientras viva; donaciones irrevocables o entre vivos constituyen aquel contrato o acto jurídico bilateral que no puede ser dejado sin efecto por la sola voluntad del causante.

43 Véase el artículo 1244 c.c., el cual establece la figura del segundo acervo imaginario, que contempla la hipótesis de cómputo de las asignaciones forzosas en aquellos eventos en que el causante en vida hubiere realizado donaciones inmoderadas a extraños, determinando si en estas se produjo algún exceso analizado de cara a las fuerzas propias de la porción o parte de libre disposción del patrimonio del causante.

44 Desheredamiento o exheredación viene a ser una sanción o pena que impone el testador a un legitimario por haber disminuido o eliminado el mérito para suceder en todo o parte de su cuota herencial. Véase art. 1265 c.c. 
tima representa la cuota mínima de los bienes del causante que la ley asigna a ciertas personas llamadas legitimarios 45 .

Con el fin de proteger las legítimas, el legislador instauró una figura para evitar que el causante adelgace sustancialmente su patrimonio y de esta manera el legitimario vea frustrado su derecho por una actuación del propio causante, quien haciendo uso de donaciones revocables e irrevocables a legitimarios y/o extraños pueda desmejorar su patrimonio. De acá surgen entonces los denominados acervos imaginarios, cuya finalidad no es otra que la efectiva protección de los intereses y expectativas de los legitimarios respecto del patrimonio de su causante.

Sobre la utilidad de esta figura, Carrizosa ha señalado que si se establece la institución de las legítimas es necesario tomar medidas para evitar que sea defraudado el derecho del legitimario por el propio accionar del causante, quien mediante donaciones a terceros o a otros legitimarios puede adelgazar de tal manera su patrimonio que a su muerte no se pueda dar aplicación a las asignaciones de ley. Es por ello que es procedente instaurar mecanismos que eviten que esa situación se presente, para lo cual deben tener en cuenta los actos jurídicos realizados por el causante ${ }^{46}$.

En ese sentido, existen dos tipos de acervos imaginarios: el primero tiene por objeto amparar a los legitimarios frente a donaciones hechas a otros legitimarios, el segundo busca defenderlos de donaciones hechas a terceros; este último produce dos efectos principales: 1 . De una parte, limita la parte de libre disposición con el fin de evitar que las donaciones hechas en vida perjudiquen la parte correspondiente a las legítimas -incluida la cuarta de mejoras en la legislación anterior-. 2. Por otro lado, da lugar a la rescisión de las donaciones realizadas. Puede acontecer que lo donado por el causante a terceros extraños a la herencia sea tan desmedido que exceda la parte de libre disposición y entre a afectar a la mitad legitimaria ${ }^{47}$, evento en cual se dará paso a la acción de inoficiosa donación.

Así, en palabras de Somarriva, "tenemos entonces, que el primer acervo imaginario defiende a los legitimarios de las donaciones hechas por el causante en vida a otros legitimarios, y el segundo tiene por objeto amparar las legítimas y cuarta de mejoras amenazadas por donaciones hechas por el causante en vida, a extraños" 48 .

45 Carrizosa, H., Sucesiones. Donaciones. Estudio sobre el libro tercero del código civil, cit., 407.

46 Ibíd., 433. Cuyo texto literal es el que sigue: "Enojosa pero necesaria consecuencia del establecimiento de legítimas, y no el menor de sus inconvenientes, como lo anota Bello, es la necesidad de tomar precauciones para evitar que sea menoscabado o totalmente frustrado el derecho del legitimario a su forzosa asignación por el propio causante, quien por la vía de las donaciones a extraños, o a los legitimarios mismos, podría durante su vida adelgazar de tal manera su caudal, que a su muerte ni hubiera manera de pagar las asignaciones determinadas por la ley. De nada serviría establecer esas reservas, si quedara al arbitrio del testador respetarlas o no. De aquí procede la necesidad de cómputo especial que ordena la ley, destinado a tomar en cuenta las liberalidades que haya hecho durante su vida la persona que al morir tiene legitimarios".

47 Este efecto también puede ser predicable de la configuración del primer acervo imaginario.

48 Somarriva, M., Derecho sucesorio. Explicaciones de clases revisadas por el profesor, Santiago, Nascimento, 1954, 78-80. 
La importancia de los acervos imaginarios radica, así, en que constituyen una garantía importante respecto de los derechos e intereses de los herederos, especialmente en aquellos sistemas que contemplan las figuras de legitimarios y asignaciones forzosas, como es el caso colombiano, puesto que impiden que el causante reduzca su patrimonio en perjuicio de los derechos que les asisten.

El uso de los acervos imaginarios posibilita que se colacionen, adicionen o retornen "imaginariamente" al patrimonio del causante las donaciones que aquel haya hecho por acto entre vivos, bien sea a sus legitimarios o a terceros, y que con fundamento en esta estimación se realicen las correspondientes asignaciones a cada legitimario.

Es por ello que la legislación anterior contemplaba que para calcular las cuartas se debían acumular imaginariamente al acervo líquido todas las donaciones revocables e irrevocables hechas a legitimarios en razón a las asignaciones forzosas o a las mejoras, es decir, se contemplaba lo que se denomina como primer acervo imaginario $^{49}$.

Ahora bien, respecto del segundo acervo imaginario el código civil contemplaba en su artículo 1244 que si el causante -que tenía a la sazón legitimarios- hubiera hecho donaciones entre vivos a extraños, y el valor de todas estas excediere el monto de lo que podía disponer libremente, debía entonces sumarse este exceso imaginariamente al acervo ya efectuado para el cómputo de las legítimas y las mejoras, lo que constituía el segundo acervo imaginario.

Como se evidencia, la legislación anterior a la Ley 1934 de 2018 contemplaba los tres elementos propios del sistema de libertad testamentaria restringida, es decir, contemplaba las personas que forzosamente debían ser beneficiarias del patrimonio del causante (art. 1226), la porción o cuota que debía ser asignada a cada una de ellas (art. 1242) y los mecanismos de protección con los que cuentan los legitimarios para hacer valer sus expectativas (arts. 1243 y 1244). De otro lado, la nueva legislación, a pesar de que mantuvo un sistema de libertad testamentaria restringida, según algunos habría cercenado el tercer requisito, esto es, los mecanismos de protección de los intereses de los legitimarios, toda vez que, presuntamente, habría eliminado del ordenamiento jurídico el primer acervo imaginario. Sin embargo, como pasaremos a explicar, de la mano de una interpretación sistemática de las disposiciones jurídicas aplicables a la materia, puede advertirse la supervivencia de aquel dentro del ordenamiento jurídico patrio.

49 Artículo 1243: "Cómputo de las cuartas. Para computar las cuartas de que habla el artículo precedente, se acumularán imaginariamente al acervo líquido todas las donaciones revocables e irrevocables, hechas en razón de legítimas o de mejoras, según el valor que hayan tenido las cosas donadas al tiempo de la entrega, y las deducciones que, según el artículo 1234, se hagan a la porción conyugal. Las cuartas antedichas se refieren a este acervo imaginario" (derogado por el art. 20 de la Ley 1934 de 2018). 


\section{Vigencia en el régimen sucesoral colombiano de la figura del primer acervo imaginario}

La Ley 1934 de 2018 expresamente dijo derogar el artículo 1243, normativa que, como se indicó, contemplaba la definición y efectos del primer acervo imaginario. Esta acción, en principio, podría considerarse como una medida que pretendía otorgar mayores libertades al testador, y en esa medida se eliminaría del ordenamiento jurídico la figura de los acervos imaginarios; no obstante, y de manera contradictoria, la misma Ley 1934 de 2018 dejó vigente el artículo 1244 c.c. ${ }^{50}$, que trata sobre el segundo acervo imaginario.

Obsérvese, en adición, que el artículo 2. ${ }^{\circ}$ de la Ley 1934 de 2018, que a su vez modificó el artículo 1226 c.c., determina dentro de las asignaciones forzosas, precisamente, a la legítima, lo que conduce, irrefutablemente, a considerar la necesidad de la existencia, procedencia y aplicación de la figura de los acervos imaginarios -primero y segundo-, los cuales han sido concebidos y establecidos como mecanismos de protección efectiva de aquella, sin que sea admisible su supuesta desaparición del estatuto civil, ya que el legislador en la reforma introducida preservó la institución de la legítima como asignación de forzoso cumplimiento.

Nótese que el modificado artículo 1244 c.c. comprende aquellos eventos en los cuales el causante, teniendo legitimarios, hubiere realizado donaciones a extraños, y el valor de todas estas juntas excediere a la mitad de la suma formada por este valor y al del acervo imaginario, dándose paso en este evento a la colación de aquellas a efectos de establecer el cómputo de las respectivas legítimas; lo anterior, desde su misma redacción, nos invita a entender que el legislador parte de la existencia del primer acervo imaginario, toda vez que pone de presente que la comparación de la donación realizada con la porción de la que podía disponer libremente el causante se hará incluso respecto del acervo imaginario ya formado. Esto significa que parte de la existencia y configuración previa del primer acervo imaginario en aquellos eventos en los cuales haya habido donaciones realizadas por el causante a legitimarios; no otra inteligencia puede otorgársele al artículo 1244 actual, ya que de lo contrario quedaría su aplicación huérfana de sentido y pertinencia.

De la mano de lo sostenido en precedencia y de la atenta lectura del artículo 12 de la Ley 1934 de 2018, que a su vez modificó el artículo 1256 c.c. ${ }^{51}$, puede

50 “Artículo 1244.- Modificado. Ley 1934 de 2018, art. 5. Si el que tenía, a la sazón, legitimarios, hubiere hecho donaciones entre vivos a extraños, y el valor de todas ellas juntas excediera a la mitad de la suma formada por este valor y al del acervo imaginario, tendrán derecho los legitimarios para que este exceso se agregue también imaginariamente al acervo, para la computación de las legítimas".

51 “Artículo 1256.- Modificado. Ley 1934 de 2018, art. 12. Todos los legados y todas las donaciones, sean revocables o irrevocables, hechas a un legitimario que tenía entonces la calidad de tal, se imputarán a su legítima, a menos que en el testamento o en la respectiva escritura o en acto posterior auténtico, aparezca que el legado o la donación se ha hecho para imputarse a la mitad de libre disposición. Sin embargo, los gastos hechos para la educación de un descendiente no se tomarán en cuenta para la computación de legítimas ni de la mitad de libre disposición, aunque se hayan hecho 
apreciarse que se ha mantenido incólume el concepto de imputación a la legítima de aquellas donaciones hechas por acto entre vivos por el causante a un legitimario, circunstancia que nos conduce a entender que para todos los efectos deberá adicionarse o colacionarse imaginariamente toda donación realizada por el causante a un legitimario -anticipo de legítima-, para así proceder a establecer el cómputo de las asignaciones forzosas, y en especial, las legítimas, lo que en últimas comporta la necesidad de configuración en estos eventos del primer acervo imaginario.

Todo lo anterior, con el auxilio de diversas normas contenidas en el código civil $^{52}$, que hacen una remisión a lo establecido en los acervos imaginarios, circunstancia que refuerza la idea de existencia y permanencia de este aspecto en nuestro ordenamiento jurídico.

Como se evidencia, se ha mantenido incólume por el legislador la protección de la figura de las legítimas en aquellos eventos en los que el causante por acto entre vivos realiza donaciones a legitimarios y/o a extraños, sin perjuicio de la presunta eliminación del artículo 1243 c.c., ya que la figura de las legítimas requiere, para su efectividad y vigencia, la existencia y aplicación de ambos acervos imaginarios, primero y segundo, tal como se advirtió antes.

De lo anterior se colige que no se ha dado en nuestro ordenamiento jurídico una desaparición de la figura del primer acervo imaginario, máxime a la luz de una interpretación sistemática de las disposiciones jurídicas aplicables a la materia, la pervivencia de las legítimas como asignaciones forzosas, y la necesidad de su efectiva y real protección a través del mecanismo de los acervos imaginarios, así como a la imposibilidad de menguar o perjudicar las asignaciones forzosas vía donaciones excesivas realizadas por el causante a legitimarios y extraños. Situaciones estas que nos conducen a considerar vigentes la figura de los acervos imaginarios en nuestro código civil.

Es sabido, entonces, que el legislador, al mantener en el ordenamiento jurídico civil la institución de las legítimas como una asignación forzosa, necesariamente acoge la existencia, procedencia y aplicación de la figura de los acervos imaginarios - primero y segundo-, ya que estos han sido concebidos como un mecanismo de protección de estas, en todos aquellos eventos en que el causante en vida haya realizado donaciones inmoderadas y excesivas tanto a legitimarios como a extraños, que comporten un perjuicio en el cómputo y pago de estas asignaciones forzosas, circunstancia que conduce inexorablemente a la formación de los acervos imaginarios herenciales propios de un régimen de restricción testamentaria. 


\section{Conclusiones}

Del estudio realizado respecto de la historia y evolución de las asignaciones forzosas se evidencia que el derecho romano, en principio, promovió un sistema de libertad testamentaria con menos restricciones, dejando que el causante a su arbitrio decidiera quién sería el heredero de su patrimonio; y que los límites que se le impusieron al causante con posterioridad atendieron a razones de índole social y religiosa, lo cual, junto con la influencia de otras culturas y sistemas, reforzó el postulado moral de proteger el patrimonio de la familia; así mismo, se constata que la legislación colombiana anterior al año 2018 tenía como fundamento histórico la coyuntura que para finales del siglo xvIII estaba viviendo la Francia revolucionaria, y por ende, las restricciones en materia sucesoral impedían la concentración de la riqueza, situación que no se compadece con las dinámicas sociales actuales.

Es por ello que resultaba necesario un cambio de legislación que estuviera más acorde con las realidades sociales de esta época, que promoviera una menor injerencia del Estado en los asuntos netamente particulares, incentivara la generación de riqueza y le permitiera al testador disponer más libremente de los bienes por él obtenidos con su trabajo y esfuerzo, de la misma manera en que lo haría por un acto entre vivos, partiendo de los postulados de libertad, autonomía privada y propiedad que orientan el derecho de sucesiones.

Es así como el legislador intentó modernizar el sistema de sucesiones, y con ese fin expidió una ley que amplía las facultades de disposición del testador, permitiéndole designar libremente hasta del cincuenta por ciento $(50 \%)$ de su patrimonio de manera libre y voluntaria, razón por la cual es dable afirmar que lo pretendido con la Ley 1934 de 2018 fue sentar los cimientos necesarios para arribar, ulteriormente, a un modelo de libertad testamentaria plena, que faculte al testador para disponer de todo su patrimonio con efectos después de su muerte.

Lo anterior podría implicar la eliminación paulatina de los elementos propios del sistema de libertad testamentaria restringida, dado que podrían derogarse los mecanismos de protección con los que cuentan los legitimarios, hasta llegar a la eliminación total de la figura de las legítimas y con ello otorgar plena libertad al testador para que disponga de sus bienes de la manera que crea más conveniente; situación esta que es la ideal si se tienen en cuenta las dinámicas socioeconómicas actuales, los lazos de solidaridad que se crean al interior y fuera del núcleo familiar, y que tienen una mejor consonancia con los principios que rigen las relaciones entre privados.

Si bien es cierto que se puede entender el genuino espíritu que ha orientado la Ley 1934 de 2018, de abogar por que el testador tenga una disposición más amplia y libre de los bienes que conforman su patrimonio, el legislador colombiano pareciera que se quedó a mitad de camino en el objetivo de otorgar plena libertad de configuración herencial, debido a que mantuvo la figura de las legítimas como asignación forzosa, además de sus mecanismos de protección, todo esto sin soltar definitivamente amarras en el propósito de acoger plenamente el principio de libertad testamentaria. 
Obsérvese que, si bien el nuevo régimen sucesoral colombiano optó por un sistema de libertad testamentaria con menos restricciones que el anterior, el legislador, contradictoriamente, parece haber eliminado un mecanismo de defensa importante para los legitimarios en este tipo de sistemas, como lo es la figura del primer acervo imaginario, sin que exista claridad en cuanto a las razones que motivaron esa cuestionada decisión. El hecho es que no se consideraron las nefastas consecuencias que esa derogatoria tendría en el plano de la protección de las legítimas, y en la estructura misma de un régimen de reservas herenciales.

Sobre la base de lo sostenido resulta pertinente preguntarse por qué se quedó corto el legislador en la reforma introducida al régimen de sucesiones colombiano cuando hubiera podido, válidamente, eliminar completamente la figura de las legítimas, y abogar así por un sistema de libertad testamentaria plena que se acopla de mejor manera con la realidad social, económica, empresarial y familiar de nuestro país.

Ojalá la respuesta al anterior interrogante venga acompañada de una nueva reforma legal que de paso adopte un régimen de libertad testamentaria total, en el que sin ninguna atadura se dé la posibilidad de hacer valedera, efectiva y plena la voluntad del causante testador.

\section{Referencias}

Anderson, M., "Una aproximación al derecho de sucesiones inglés", Anuario de Derecho Civil, Agencia de Estatal Boletín Oficial del Estado, vol. 59, n. ${ }^{\circ} 3$, 2006, 1245 ss.

Bello, A. Obras completas, vol. xxvi, t. II, Epistolario, 2. a ed., Caracas, Fundación La Casa de Bello, 1984.

Berman, H., La formación de la tradición jurídica de Occidente, México, Fondo de Cultura Económica, 1996.

Bonfante, P., Corso di diritto romano. Le successioni, Milano, Giuffrè, 1974.

Carrizosa, H., Sucesiones. Donaciones. Estudio sobre el libro tercero del código civil, 5. a ed., Bogotá, Lerner, 1966.

Claro, L., Derecho civil chileno y comparado. De la sucesión por causa de muerte, Santiago, Nascimento, 1942.

Cobas Cobiella, M., "La modernización del derecho de sucesiones. Algunas propuestas”, Cuestiones de Interés Jurídico, IDIBE, julio, 2017. 
Colmenares, J., Libertad testamentaria en Roma. Una aproximación a propósito del estado actual de la cuestión en Colombia, México, Instituto de Investigaciones Jurídicas, Universidad Nacional Autónoma de México, 2017.

Deloitte, Sucesión en la empresa familiar, Boletín Gobierno Corporativo, 2010.

Gómez, M. E., “Aspectos patrimoniales en las relaciones de familia consagradas en el código de Andrés Bello y su vigencia en la sociedad contemporánea”, en Navia, F. y Chinchilla, C. A. (eds.), La vigencia del código civil de Andrés Bello. Análisis y prospectivas en la sociedad contemporánea, Bogotá, Universidad Externado de Colombia, 2019.

Iglesias, J., Derecho romano. Historia e instituciones, 11. a ed., Barcelona, Ariel, 1993.

Iglesias, Y. y Navarro, D., "La inclusión de la 'legítima' como elemento desestabilizador de la nobleza en la Partida vi de Alfonso x", Revista Canadiense de Estudios Hispánicos, vol. 41, n. ${ }^{\circ}$ 3, 2017, 547-567.

Lira-Urquieta, P., “Introducción”, en Andrés Bello, xiI, Código civil de la República de Chile, I, Caracas, Ministerio de Educación, 1954.

MAINAR, R., "De la legítima romana a la reserva familiar germánica”, Revista Internacional de Derecho Romano, . $^{\circ}$ 14, 2015, 1-63.

Miquel González, J., "Legítima material y legítima formal”, [en línea], El Notario del Siglo XXI, 2009, disponible en: http:/www.elnotario.es/academia-matritensedel-notariado/1544-legitima-material-y-legitima-formal-0-9796865787167909 [consultado el 30 de marzo de 2020].

PacheCo, J., Obras jurídicas. Comentario histórico, crítico y jurídico a las Leyes de Toro, t. I, Sevilla, Imprenta de Manuel Tello, 1862.

Red Judicial EuRopea, “¿Hay restricciones en cuanto a la libertad de disponer 'mortis causa'?”, [en línea], Información general - Italia, disponible en: https://ejustice.europa.eu/content_succession-166-it-es.do\#toc_3 [consultado el 30 de marzo de 2020].

Somarriva, M., Derecho sucesorio. Explicaciones de clases revisadas por el profesor, Santiago, Nascimento, 1954. 
VÁzQuez, A., Fundamentos históricos y jurídicos de la libertad de testar, Vigo, Universidad de Vigo, 2018.

Weber, M., The Agrarian Sociology of Ancient Civilizations, 1909. 